\title{
Human and Bovine Dentin Composition and Its Hybridization Mechanism Assessed by FT-Raman Spectroscopy
}

\author{
L. E. S. Soares, ${ }^{1,2}$ A. D. F. Campos, ${ }^{2}$ and A. A. Martin ${ }^{2}$ \\ ${ }^{1}$ Department of Dental Materials and Operative Dentistry, School of Dentistry, University of Vale do Paraíba (UNIVAP), \\ Urbanova, 12.244-000 São José dos Campos, SP, Brazil \\ ${ }^{2}$ Laboratory of Biomedical Vibrational Spectroscopy, Research and Development Institute (IP\&D), \\ University of Vale do Paraíba (UNIVAP), Urbanova, 12.244-000 São José dos Campos, SP, Brazil
}

Correspondence should be addressed to L. E. S. Soares; lesoares@univap.br

Received 26 June 2012; Accepted 22 November 2012

Academic Editor: Christoph Krafft

Copyright (C) 2013 L. E. S. Soares et al. This is an open access article distributed under the Creative Commons Attribution License, which permits unrestricted use, distribution, and reproduction in any medium, provided the original work is properly cited.

FT-Raman spectroscopy was used to study the human and bovine dentin and their interactions with adhesive systems. Ten human $(\mathrm{H})$ molars and ten bovine $(\mathrm{B})$ teeth were prepared exposing the dentin and then each specimen was divided into two parts. The resulted forty dentin segments were treated either with the total-etch one bottle adhesive (Prime \& Bond 2.1, PB ) or with the singlestep self-etching adhesive (Xeno III, X) and divided into four groups: HPB (control), HX, BPB, and BX. Each group was analyzed by FT-Raman spectroscopy before and after the adhesive treatment. Six regions of the Raman spectrum were analyzed and the integrated areas of organic and inorganic peaks were calculated. Bovine untreated specimens showed higher peak area of $\mathrm{PO}_{4}{ }^{3-} v_{2}$ content than in human specimens. Human untreated specimens had higher peak areas of $\mathrm{PO}_{4}{ }^{3-} v_{4}$ and $\mathrm{CO}_{3}{ }^{2-} v_{1}$ contents than in bovine specimens. The peak areas of amide III, $\mathrm{CH}_{2}$, and amide I contents were higher in human than in bovine specimens (before treatments). Treated dentin showed no significant statistical differences between the adhesives for both inorganic and organic contents considering the same substrate. However, the differences found between human and bovine specimens after adhesives application show a reduced accuracy of these substrates as a substitute to the human specimens.

\section{Introduction}

The characteristics of dental hard tissues are the main factor to be observed when analyzing the possibilities of the replacement of human teeth by animal teeth for in vitro studies. As a candidate for human teeth replacement, bovine permanent incisors have been employed in previous adhesion studies [1-4].

It has been reported that the adhesion to the superficial layer of dentin showed no significant differences between human and bovine dentin, and the dentin bond strength decreased with the depth of dentin because of the lower density of dentinal tubules in the bovine dentin [5]. The morphology of coronal dentin and enamel is similar when comparing bovine and human teeth. Moreover, bovine teeth provide other advantages, such as similar age of the teeth and greater availability [6]. Histochemical and comparative anatomical studies have revealed that all mammalian teeth are essentially similar. Human and bovine dentin also presented similar radiodensity [7]. There is still some concern whether the results of experiments with animal teeth can be extended to the human teeth and to the clinical situation; however, ethics committees around the world have stimulated the replacement of human teeth by animal ones [7].

Considering these factors, investigations on the chemical composition for hybridization of adhesive systems with bovine dentin are important to validate the studies to the human dentin. Contemporary adhesive systems interact with the dentin using two different approaches: either by completely removing the smear layer (etch-and-rinse technique) or by modifying it (self-etch technique) [8].

In selecting an adhesive system for the clinical use, it is very important to evaluate its bond strength and sealing ability [9]. Bond strengths are generally tested in tension or in shear $[9,10]$. Even though the results are very useful 
regarding the effectiveness of adhesive systems, there is a lack of information about the chemical interaction of the self-etch adhesive systems with the bovine dentin as a substitute to the human dentin.

Microscopy characterization can demonstrate the morphological relationship between the dentin and the adhesive layer, whereas Raman spectroscopy can elucidate the molecular interactions between the dentin and the adhesive monomers [11]. Raman spectroscopy permits the structural analysis of samples by identifying specific light-induced molecular vibrations [12]. In addition, the relative intensities of bands can lead to semiquantitative estimations of sample constituents [13].

One of the distinct advantages of the Raman technique from other analytical techniques is the ability to record the molecular information of both collagen and mineral component of teeth without damaging the sample [12]. Several studies using Raman spectroscopy to analyze the resin-dentin interface have been reported $[2,4,11,14-16]$.

Based on previous studies on the application of adhesives using human or bovine dentin as a substrate, a more detailed characterization of the adhesive interaction with either human or bovine dentin components needs to be performed. Such characterization is important since detailed information on dentin structure is essential to understand the data from the investigations on dentin-adhesive materials [17].

Therefore, the purpose of this study was to investigate by FT-Raman spectroscopy whether there are differences in the inorganic and organic composition of human and bovine dentin before and after total-etch-and self-adhesive systems application.

\section{Materials and Methods}

2.1. Specimen Preparation. Ethical approval of the study was granted by the Ethics Committee of the University of Vale do Paraíba (L087/2005/CEP). Ten extracted erupted noncarious human third molars and ten bovine teeth were used in this study. The human teeth were obtained from patients whose extractions were part of the dental treatment, and the bovine incisors teeth were obtained from bovine jaws. All specimens were stored in saline solution (Aster Produtos Médicos LTDA, Sorocaba, SP, Brazil) at $9^{\circ} \mathrm{C}$ until use. After the extraction, the remaining soft tissue was removed from the tooth surface with a dental scaler (7/8; Duflex, Rio de Janeiro, RJ, Brazil). The teeth were polished with a paste of pumice (S.S. White, Rio de Janeiro, RJ, Brazil) and filtered water using a Robinson brush (Viking-KG Sorensen, Barureri, SP, Brazil) in a low speed handpiece (KaVo do Brasil SA, Joinvile, SC, Brazil). After the cleaning procedure, the teeth were stored in $0.1 \%$ thymol aqueous solution at $9^{\circ} \mathrm{C}$ for one week long. To prepare the dentin specimens the teeth were washed for $24 \mathrm{~h}$ with filtered water to eliminate thymol residues [18].

The occlusal one-third of the human teeth crowns were sectioned perpendicularly to the long axis using a watercooled low-speed diamond disc at $250 \mathrm{rpm}$ with a $100 \mathrm{~g}$ load (Isomet 1000-BUEHLER, Lake Bluff, IL, USA). The dentin surface was grinded on wet 600-grit silicon carbide paper (Norton, São Paulo, SP, Brazil) at $150 \mathrm{rpm}$ (Knuth RotorStruers, Brazil) for $1 \mathrm{~min}$, under constant water cooling to produce a standardized smear layer [18]. Roots were removed with a water-cooled low-speed diamond disc producing a dentin slab for each tooth. Each specimen was then divided into two parts.

Similarly, ten bovine teeth were cleaned after the extraction and stored in $0.1 \%$ thymol aqueous solution like the human teeth. The buccal enamel surface was removed using a water-cooled low-speed diamond disc at $250 \mathrm{rpm}$ with a $100 \mathrm{~g}$ load and grinded on wet 600 -grit silicon carbide paper at $150 \mathrm{rpm}$ to expose the dentin layer. The dentin surface was polished for $1 \mathrm{~min}$, under constant water cooling to produce a standard smear layer. The specimens were sectioned parallel to the long axis and the pulps were removed resulting into two parts. Ultrasonic cleaning (Maxiclean 1450, Merse, Campinas, SP, Brazil) with distillated water was performed for human and bovine teeth for $5 \mathrm{~min}$ in order to remove the excess of debris. The specimens were then stored in saline solution in a refrigerator at $9^{\circ} \mathrm{C}$ for one week.

The total of 20 human $(\mathrm{H})$ dentin samples $(\sim 0.4 \times$ $0.5 \times 0.4 \mathrm{~mm})$ and 20 bovine $(B)$ teeth samples $(\sim 0.5 \times$ $0.5 \times 0.3 \mathrm{~mm}$ ) were treated with Prime \& Bond 2.1, PB (DENTSPLY De Trey GmbH, Konstanz, Germany), a totaletch one bottle adhesive or with Xeno III, X (DENTSPLY De Trey GmbH, Konstanz, Germany), a one-step self-etching adhesive, according to the experimental groups division: HPB (control), HX, BPB, and BX.

The chemical formulations of the two adhesives are listed in Table 1. All adhesives were applied onto dentin surfaces, in accordance with the manufacturers' instructions. Each adhesive was cured with a halogen light-curing unit (LCU) (Degulux soft-start, Degussa AG, Hanau, Germany) with a power density of $745 \mathrm{~mW} / \mathrm{cm}^{2}$. The light intensity of the LCU was measured by a power meter (Field Master GS, Coherent Inc., Auburn, CA, USA).

2.2. FT-Raman Spectroscopy Analysis. FT-Raman spectroscopy analyzed the top surface of dentin slabs before and after the treatments. One spectrum for each specimen was collected. The FT-Raman spectrometer (RFS 100/S-Bruker Inc., Karlsruhe, Germany) with a Ge diode detector cooled by liquid $\mathrm{N}_{2}$ was used to collect the data. The samples were excited by an air-cooled Nd:YAG laser $(\lambda=1064.1 \mathrm{~nm})$. The power of the incident Nd:YAG laser on the sample was $100 \mathrm{~mW}$. The spectral resolution was set to $4 \mathrm{~cm}^{-1}$ and for each measurement one spectrum was accumulated with 100 scans [18]. After the dentin treatment with each adhesive system, the same procedure was repeated and one spectrum for each specimen was accumulated on the top surface of dentin slabs, adding 80 spectra. The spectra of uncured adhesives were also collected using capillary tubes.

For the qualitative and semiquantitative spectral analysis, the spectra were baseline corrected and then normalized to the $960 \mathrm{~cm}^{-1}$ peak [19]. In the dentin Raman spectrum, six regions were evaluated: mineral component at $365-488 \mathrm{~cm}^{-1}$ (p1), 520-650 $\mathrm{cm}^{-1}$ (p2), and 995-1120 $\mathrm{cm}^{-1}$ 
TABLE 1: Composition of the adhesives systems tested.

\begin{tabular}{ll}
\hline Adhesive & Composition \\
\hline & Liquid A: \\
& 2-hydroxyethyl methacrylate (HEMA); butylated hydroxy toluene (BHT); highly dispersed silicon dioxide; purified \\
& water; ethanol \\
& Liquid B: \\
& Phosphoric acid modified methacrylate resin; mono fluoro phosphazene modified methacrylate resin (PEM-F); \\
& urethane dimethacrylate resin (UDMA); butylated hydroxy toluene (BHT); camphorquinone (CQ); \\
& ethyl-4-dimethylaminobenzoate \\
\hline & Etching: \\
& 37\% phosphoric acid \\
& Bond: \\
& Elastomeric bisGMA-diisocyanate adduct; urethane dimethacrylate resin (UDMA), bisphenol A dimethacrylate \\
& (bis-DMA), and pentaerythritol penta acrylate monophosphate (PENTA); photoinitiator; catalysts; cetylamine \\
& hydrofluoride; acetone
\end{tabular}

(p3) and organic component at $1215-1365 \mathrm{~cm}^{-1}$ (p4), $1366-1502 \mathrm{~cm}^{-1}$ (p5), and $1580-1735 \mathrm{~cm}^{-1}$ (p6). The integrated areas of the peaks were calculated by the MatLab software (The MathWorks, Inc., Natick, MA, USA).

The statistical analysis of the Raman results was performed by the one-way ANOVA at a 95\% level of confidence. The Dunn's Multiple Comparisons post hoc test was performed using the Instat software (GraphPad Software, San Diego, CA, USA) to assess the significance of the relative area evaluation of the treated dentin data. The Mann-Whitney test was also performed to study the significance between the average of twenty untreated bovine and the average of 20 untreated human spectra integrated areas.

\section{Results}

3.1. Untreated Dentin. The typical Raman spectra for the untreated human and bovine dentin in the regions of $300-1200 \mathrm{~cm}^{-1}$ and $1200-1800 \mathrm{~cm}^{-1}$ are shown in Figures 1 and 2, respectively. The spectra have been vertically shifted for clarity. Bovine and human spectra showed the same vibrational bands of mineral and organic components. In Figure 1, the intense peak at $960 \mathrm{~cm}^{-1}$ is associated with the phosphate $\left(\mathrm{PO}_{4}{ }^{3-} v_{1}\right)$ stretching vibration in the mineral apatite component of dentin, and the peak at $1071 \mathrm{~cm}^{-1}$ is attributed to carbonate $\left(\mathrm{CO}_{3}{ }^{2-} v_{1}\right)$ vibrations [13]. The peaks at 431 and $590 \mathrm{~cm}^{-1}$ are related to $\mathrm{PO}_{4}{ }^{3-} \nu_{2}$ and $\mathrm{PO}_{4}{ }^{3-} v_{4}$ modes of phosphate, respectively [13]. In Figure 2, the bands at 1245,1452 , and $1667 \mathrm{~cm}^{-1}$ are attributed to the organic components of dentin, that is, type III collagen, $\mathrm{CH}_{2}$ vibrations, and type I collagen $(\mathrm{C}=\mathrm{O})$, respectively [13].

3.2. Adhesive Treated Dentin. Figure 3 shows the representative Raman spectra of the pure dental adhesives Prime \& Bond 2.1 (Figure 3(a)) and Xeno III (Figure 3(b)), where the spectral features associated with both the aromatic and aliphatic components within both adhesive systems at 1608 and $1638 \mathrm{~cm}^{-1}$, respectively [1], can be identified. By a careful examination of this figure, after the adhesive treatment, the

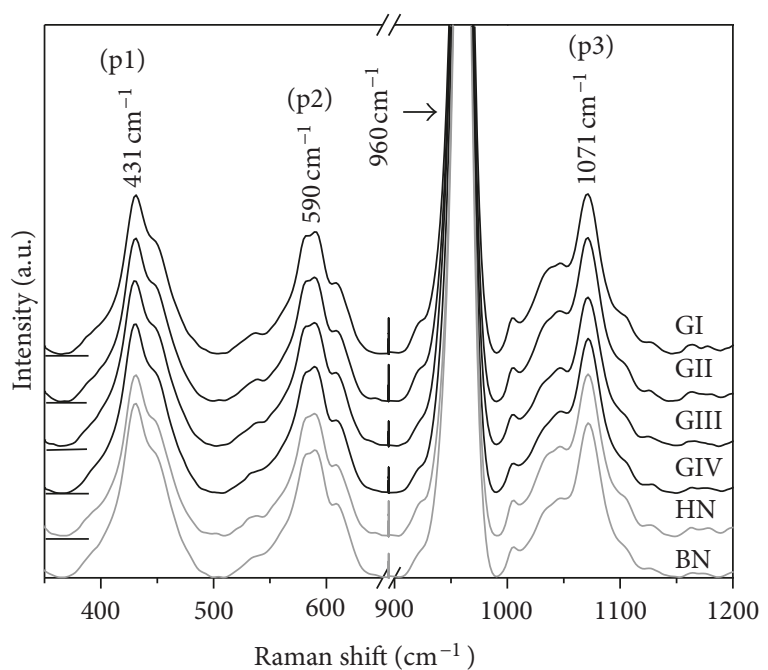

FIGURE 1: Comparison of FT-Raman spectra of mineral components from normal bovine dentin (BN) and normal human dentin (HN); human dentin treated with Xeno III (GI) and Prime \& Bond 2.1 (GII) adhesives; bovine dentin treated with Xeno III (GIII) and Prime \& Bond 2.1 adhesives (GIV).

appearance of a shoulder at $1638 \mathrm{~cm}^{-1}$ in the dentin spectra (Figures 3(c) and 3(d)) for both substrates is noted.

3.3. Integrated Area Evaluation. Based on the calculated integrated areas of the Raman peaks, the results of the Mann-Whitney test showed statistical significant difference between the average of untreated human $(n=20)$ and bovine $(n=20)$ spectra related to the inorganic and organic dentin contents $(P<0.0001)$ (Table 2$)$. Bovine specimens showed higher peak area of $\mathrm{PO}_{4}{ }^{3-} v_{2}$ contents than in human specimens. However, human specimens had higher peak areas of $\mathrm{PO}_{4}{ }^{3-} v_{4}$ and $\mathrm{CO}_{3}{ }^{2-} v_{1}$ contents than in bovine specimens. The peak areas of amide III, $\mathrm{CH}_{2}$, and amide I contents were higher in human than in bovine specimens.

Comparing the normal and treated spectra, it was observed that the adhesive treatment maintained or changed without statistical significance $(P>0.05)$ the integrated area 


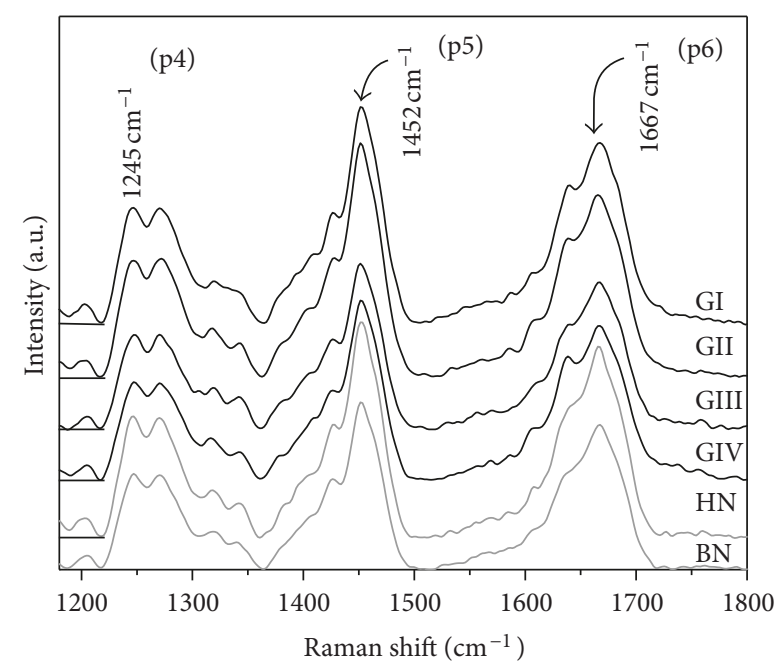

FIGURE 2: Comparison of FT-Raman spectra of organic components from normal bovine dentin (BN) and normal human dentin (HN); human dentin treated with Xeno III (GI) and Prime \& Bond 2.1 (GII) adhesives; bovine dentin treated with Xeno III (GIII) and Prime \& Bond 2.1 adhesives (GIV).

of the peaks related to inorganic ( $11, \mathrm{p} 2$, and $\mathrm{p} 3$ ) and organic (p4, p5, and p6) components of dentin for both adhesive systems (Table 2).

Statistical comparisons of the integrated areas of the Raman peaks between the adhesives and considering the same substrate (HPB versus HX; BPB versus BX) of treated dentin showed no significant statistical differences between the adhesives for both inorganic and organic contents $(P>$ 0.05) (Tables 2 and 3 ).

Comparisons of treated dentin between the two substrates and considering the same adhesive (HPB versus BPB; $H X$ versus $B X$ ) showed statistical significant differences of the integrated areas of the Raman peaks, except for the peak at $590 \mathrm{~cm}^{-1}(P>0.05)$ (Tables 2 and 3).

The integrated area of the $\mathrm{p} 1$ peak related to the $\mathrm{PO}_{4}{ }^{3-} v_{2}$ content in BX specimens was higher than in $\mathrm{HX}(P<0.05)$. The integrated area of the $\mathrm{p} 3$ peak related to the vibrational mode of carbonate in HX and HPB specimens was higher than in BX and BPB $(P<0.001)$. The integrated area of the $\mathrm{p} 4$ peak related to the type III collagen was higher in HPB than in BPB specimens $(P<0.05)$. The integrated areas of the $\mathrm{p} 5$ and p6 peaks related to the $\mathrm{CH}_{2}$ bonds and type I collagen, respectively, were higher in $\mathrm{HPB}$ and $\mathrm{HX}$ than in $\mathrm{BPB}$ and BX specimens $(P<0.05)$ (Tables 2 and 3$)$.

\section{Discussion and Conclusion}

Despite previous histochemical, anatomical, morphological, and mechanical comparative studies considering human and bovine teeth $[1-3,7,9-11,14]$, no studies have evaluated and characterized each vibrational mode of the dentin components of both substrates or established the relationship between dentin chemistry, specimens variability, and a possible influence on the adhesion. This relationship is important owing to the increase in the replacement of human teeth by animal teeth for in vitro studies.

FT-Raman analysis revealed that untreated human and bovine dentin had significant differences in the inorganic and organic contents in superficial dentin (Table 2). Those differences found between substrates are probably due to the fact that the dentin in bovine incisors presents larger dentinal tubules and are more porous in the intertubular dentin than human molars [20]. Mature human dentin contains more carbonate than enamel (5-8 wt\%) [13]. The mineral in human dentin is a carbonated apatite and is located either in the gaps between the collagen molecules (intrafibrillar) or attached to the collagen fibrils (extrafibrillar) [21]. This fact is important because the collagen matrix is the key component of acidetched dentin.

When analyzing the results of the Mann-Whitney test, to verify chemical differences between untreated human and bovine dentin, our study showed higher peak areas related to the inorganic (p2, p3) and organic contents (p4-p6) in human specimens than in bovine specimens (Table 2). Bovine specimens showed higher inorganic peak area related to the $\mathrm{PO}_{4}{ }^{3-} v_{2}$ vibrational mode than in human specimens. Those differences in inorganic content related to phosphate and carbonate vibrational modes could be explained by the differences of arrangement, density, and diameter of dentin tubules between human and bovine dentin. Tanaka et al. [22] observed that the radiodensity of bovine coronal dentin was, on average, lower than that of the human coronal dentin. Fonseca et al. [7] also observed that bovine dentin is less dense than human dentin. Those mentioned differences could influence the etching process by phosphoric acid or by acidic primers where the amounts of minerals remained would be different between substrates. Pashley et al. [23] showed better infiltration of resin in human dentin because of the higher percentage of dentin tubule surface in human than in bovine specimens. This higher percentage of dentin tubules could result in a better penetration of an acid into human dentin allowing a higher amount of dentin dissolution in human specimens at the same time as compared to bovine specimens [24].

The elevated organic content found in human untreated dentin could be another factor which influences the adhesion process since the exposed and stabilized collagen layer of dentin is a key factor to an adequate adhesion. Micromechanical retention is considered the most important mechanism for bonding resin to dentin. Such retention can occur when resin completely infiltrates dentin surfaces and creates a resin-reinforced dentin layer [25]. A hybrid layer can be produced by etching the dentin prior to priming and bonding the dentin surface. During priming, hydrophilic monomers that diffuse across the demineralized dentin stabilize the hydrated collagen network and displace water with polymerizable monomers. Finally, the adhesive resins are applied to the primed dentin and polymerized [25]. The strength of the adhesive bonds between restorative materials and dentin is affected by the number of dentinal tubules per $\mathrm{mm}^{2}$ and by their diameter, as well as the relative amount of intratubular and intertubular dentin [3]. According to Nakamichi et al. [5], 


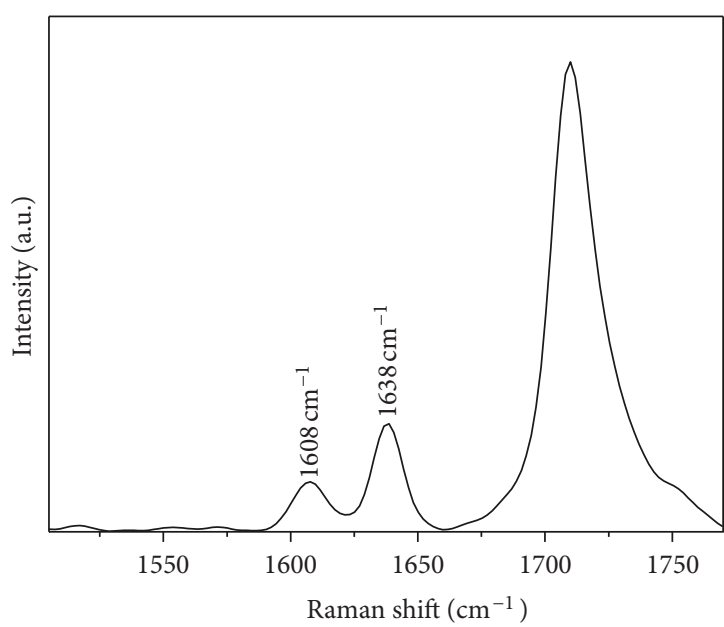

(a)

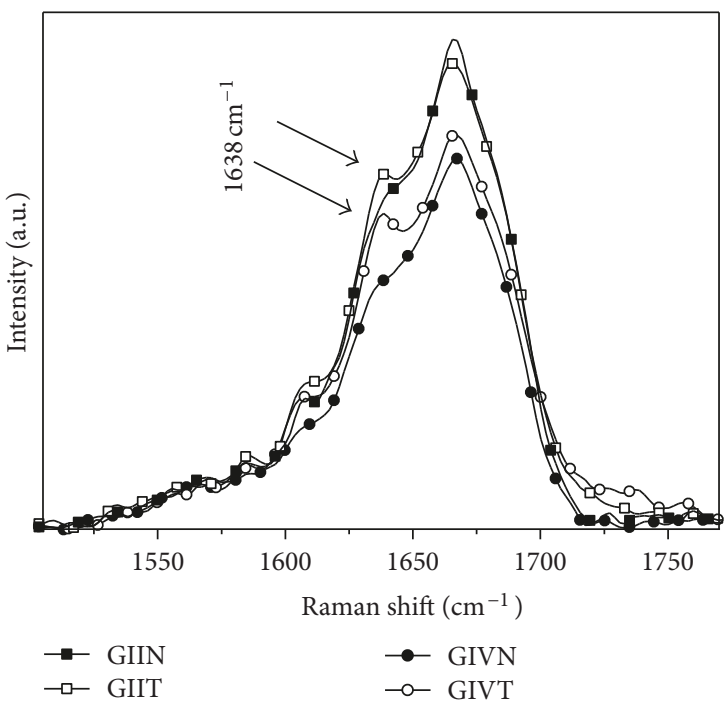

(c)

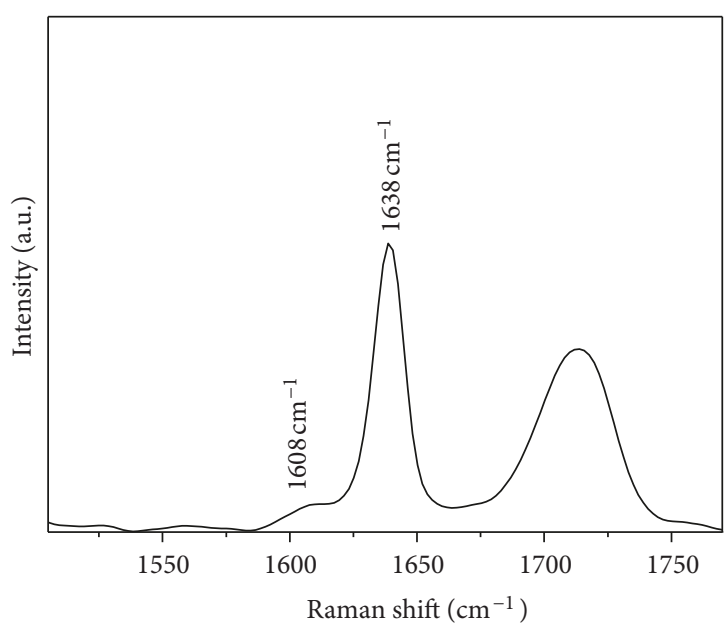

(b)

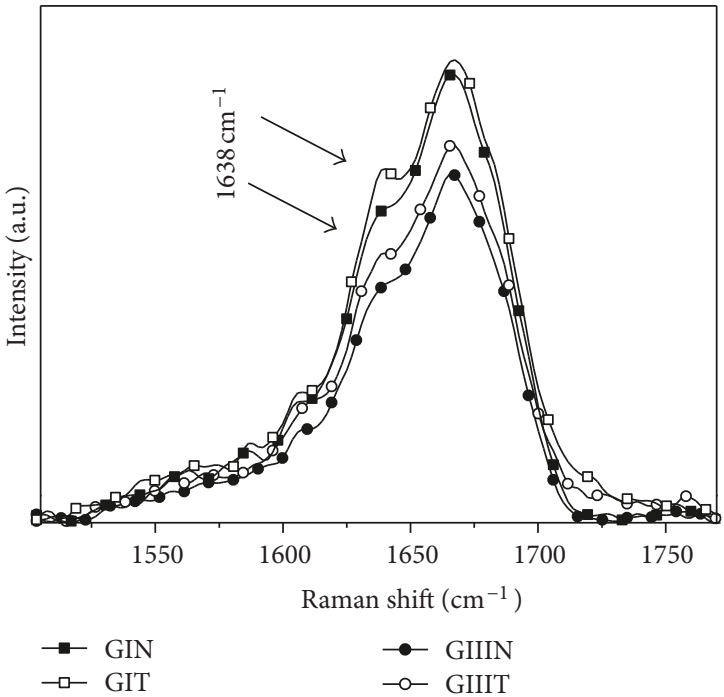

(d)

Figure 3: FT-Raman spectra of Prime \& Bond 2.1 (a) and Xeno III adhesives (b); dentin treated with Prime \& Bond 2.1 (c) and Xeno III (d) adhesives.

a sufficient area of substrate could be obtained in different dentin depths of bovine incisors, but only the superficial layer could be considered a substitute to human dentin. The dentin in bovine incisors presents larger dentinal tubules and more porous on intertubular dentin than human molars [3].

The statistical data presented in Table 3 showed that when the same substrate was considered, both adhesives interacted similarly with the dentin components despite their difference in the composition and mechanism of action. However, when the same adhesive was considered but with different substrates, significant statistical differences were found among the components of treated dentin, except for the phosphate peak at $590 \mathrm{~cm}^{-1}$. Previous studies comparing the total-etch one bottle adhesive with the self-etching adhesive reported higher bond strength values for the self-etching primer Clearfil; however this difference was not statistically significant $[9,10,26]$. One explanation for these findings was the difference in the adhesive composition. The total-etch one bottle adhesives studied contained acetone and the selfetching adhesive contained water. Products that use acetone as the solvent may require a moist dentin substrate to produce adequate bonding. These products may be extremely sensitive to the amount of water on the dentin surface, and even a small amount of drying may have a significant role in reducing the bond strength $[9,10,26]$.

The integrated area from the Raman peaks of human and bovine dentin after adhesives application, shows statistical significant differences between those two specimens (Tables 2 and 3), indicating a reduced accuracy of these substrates as a substitute to the human specimens. Since adhesive systems are developed according to the characteristics of human teeth, this fact should be considered when interpreting data from studies, in which bovine teeth were used as substitutes in the adhesion research. 
TABLE 2: Mean values (standard deviation) of integrated areas obtained from Raman spectra: inorganic peaks (p1-p3) and organic peaks $(\mathrm{p} 4-\mathrm{p} 6)$ of normal $(\mathrm{N})$ and treated $(\mathrm{T})$ dentin of experimental groups $(n=10)$, untreated human $(\mathrm{HN})(n=20)$, and bovine (BN) dentin $(n=20)$.

\begin{tabular}{|c|c|c|c|c|c|c|}
\hline Groups & $\begin{array}{c}\mathrm{p}^{3-} \\
\mathrm{PO}_{4}{ }^{3-} v_{2} \\
431 \mathrm{~cm}^{-1}\end{array}$ & $\begin{array}{c}\mathrm{p}^{2} \\
\mathrm{PO}_{4}^{3-} v_{4} \\
590 \mathrm{~cm}^{-1}\end{array}$ & $\begin{array}{c}\mathrm{p} 3 \\
\mathrm{CO}_{3}{ }^{2-} v_{1} \\
1071 \mathrm{~cm}^{-1}\end{array}$ & $\begin{array}{c}\mathrm{p} 4 \\
\text { Amide III } \\
1245 \mathrm{~cm}^{-1}\end{array}$ & $\begin{array}{c}\text { p5 } \\
\mathrm{CH}_{2} \\
1452 \mathrm{~cm}^{-1}\end{array}$ & $\begin{array}{c}\text { p6 } \\
\text { Amide I } \\
1665 \mathrm{~cm}^{-1}\end{array}$ \\
\hline $\mathrm{HN}$ & $3.49(0.25)^{*}$ & $2.99(0.08)^{*}$ & $3.83(0.18)^{*}$ & $2.04(0.19)^{*}$ & $2.70(0.17)^{*}$ & $2.56(0.22)^{*}$ \\
\hline $\mathrm{BN}$ & $3.83(0.10)^{*}$ & $2.78(0.21)^{*}$ & $3.46(0.10)^{*}$ & $1.60(0.30)^{*}$ & $2.06(0.37)^{*}$ & $2.02(0.32)^{*}$ \\
\hline HPB-N & $3.51(0.13)$ & $2.80(0.14)$ & $3.87(0.16)$ & $2.04(0.19)$ & $2.67(0.21)$ & $2.59(0.26)$ \\
\hline HPB-T & $3.53(0.14)$ & $2.81(0.09)$ & $3.76(0.16)$ & $2.14(0.19)$ & $2.85(0.25)$ & $2.64(0.19)$ \\
\hline $\mathrm{HX}-\mathrm{N}$ & $3.47(0.33)$ & $2.77(0.26)$ & $3.79(0.19)$ & $2.05(0.21)$ & $2.74(0.12)$ & $2.52(0.17)$ \\
\hline $\mathrm{HX}-\mathrm{T}$ & $3.35(0.13)$ & $2.70(0.10)$ & $3.74(0.12)$ & $2.03(0.25)$ & $2.77(0.34)$ & $2.58(0.22)$ \\
\hline BPB-N & $3.85(0.10)$ & $2.98(0.07)$ & $3.48(0.10)$ & $1.66(0.30)$ & $2.11(0.41)$ & $2.08(0.36)$ \\
\hline BPB-T & $3.74(0.05)$ & $2.88(0.07)$ & $3.41(0.12)$ & $1.73(0.24)$ & $2.25(0.36)$ & $2.14(0.37)$ \\
\hline $\mathrm{BX}-\mathrm{N}$ & $3.81(0.10)$ & $2.99(0.08)$ & $3.45(0.11)$ & $1.53(0.29)$ & $2.00(0.34)$ & $1.95(0.27)$ \\
\hline $\mathrm{BX}-\mathrm{T}$ & $3.64(0.12)$ & $2.92(0.12)$ & $3.41(0.14)$ & $1.64(0.27)$ & $2.09(0.32)$ & $2.06(0.28)$ \\
\hline
\end{tabular}

*Denotes statistical significant difference $(P<0.0001)$ between human and bovine untreated substrates (Mann-Whitney Test).

TABLE 3: Statistical results of the Dunn's Multiple Comparisons post-hoc test evaluation of integrated areas of the Raman peaks of the groups treated with adhesives (significant comparisons are in bold).

\begin{tabular}{|c|c|c|c|c|c|c|}
\hline Group comparison & $\begin{array}{c}\mathrm{p} 1 \\
\mathrm{PO}_{4}^{3-} v_{2} \\
431 \mathrm{~cm}^{-1}\end{array}$ & $\begin{array}{c}\mathrm{p} 2 \\
\mathrm{PO}_{4}^{3-} v_{4} \\
590 \mathrm{~cm}^{-1}\end{array}$ & $\begin{array}{c}\mathrm{p} 3 \\
\mathrm{CO}_{3}^{2-} v_{1} \\
1071 \mathrm{~cm}^{-1}\end{array}$ & $\begin{array}{c}\mathrm{p} 4 \\
\text { Amide III } \\
1245 \mathrm{~cm}^{-1}\end{array}$ & $\begin{array}{c}\mathrm{p} 5 \\
\mathrm{CH}_{2} \\
1452 \mathrm{~cm}^{-1}\end{array}$ & $\begin{array}{c}\text { p6 } \\
\text { Amide I } \\
1665 \mathrm{~cm}^{-1}\end{array}$ \\
\hline HX versus $\mathrm{HPB}$ & ${ }^{\mathrm{ns}} P>0.05$ & ${ }^{\mathrm{ns}} P>0.05$ & ${ }^{\mathrm{ns}} P>0.05$ & ${ }^{\mathrm{ns}} P>0.05$ & ${ }^{\mathrm{ns}} P>0.05$ & ${ }^{\mathrm{ns}} P>0.05$ \\
\hline $\mathrm{BX}$ versus $\mathrm{BPB}$ & ${ }^{\mathrm{ns}} P>0.05$ & ${ }^{\mathrm{ns}} P>0.05$ & ${ }^{\mathrm{ns}} P>0.05$ & ${ }^{\mathrm{ns}} P>0.05$ & ${ }^{\mathrm{ns}} P>0.05$ & ${ }^{\mathrm{ns}} P>0.05$ \\
\hline HX versus BX & ${ }^{*} \mathbf{P}<\mathbf{0 . 0 5}$ & ${ }^{\mathrm{ns}} P>0.05$ & ${ }^{* *} \mathbf{P}<\mathbf{0 . 0 1}$ & ${ }^{\text {ns }} P>0.05$ & ${ }^{*} \mathbf{P}<\mathbf{0 . 0 5}$ & ${ }^{*} \mathbf{P}<\mathbf{0 . 0 5}$ \\
\hline $\mathrm{HPB}$ versus $\mathrm{BPB}$ & ${ }^{\mathrm{ns}} P>0.05$ & ${ }^{\mathrm{ns}} P>0.05$ & ${ }^{* *} \mathbf{P}<\mathbf{0 . 0 1}$ & ${ }^{*} \mathbf{P}<\mathbf{0 . 0 5}$ & ${ }^{*} \mathbf{P}<\mathbf{0 . 0 5}$ & ${ }^{*} \mathbf{P}<\mathbf{0 . 0 5}$ \\
\hline
\end{tabular}

${ }^{*},{ }^{* *}$ Significant statistical difference; ${ }^{\text {ns }}$ nonsignificant statistical difference.

Regarding the analysis of adhesive interaction with dentin, some authors have found, by FT-Raman spectroscopy, piesces of evidence suggesting that ionic bonds and hydrogen bonding may form through the interaction of the ester function of adhesive ligand with the amide groups of collagen or through the formation of hydrogen bonds between the ligand and the collagen receptor [11]. In the present study a shoulder band at $1640 \mathrm{~cm}^{-1}$ was observed in the spectra, after the adhesive treatment (Figure 3), and this band is related to the $\mathrm{C}=\mathrm{C}$ bond of the adhesive as observed in other studies $[1,11,14]$. This aspect indicated the chemical interaction of the adhesive with dentin.

In summary, we presented direct information regarding the differences in the chemical composition of the human and bovine dentin interaction with one single-step selfetching adhesive and one total-etch one bottle adhesive by using FT-Raman spectroscopy. The major contribution of this study was the chemical characterization of the differences between the mineral and organic components of untreated and adhesive-treated human and bovine dentin as substrates. Untreated bovine dentin showed lower organic content than the human dentin and this is a possible limitation for in vitro studies of adhesion since adhesion mechanism in dentin is based on adhesive infiltration in the exposed collagen layer after demineralization by acid etching or acidic primers.
Further investigation is necessary to better understand how those differences in organic and inorganic content between these substrates influence the bond strength. In view of the results obtained in the present study, the authors believe that additional research must be conducted on the subject of the micromorphology and chemical composition of bovine dentin, using analytical tools as scanning electron microscopy, energy dispersive X-ray fluorescence, and micro-Raman among others, with the aim of acquiring more data about bovine teeth to the better use of bovine specimens in research conducted in this field.

\section{Acknowledgments}

The authors thank Walter Andrés Avendaño Jara for the MatLab analysis. This work was supported by FAPESP $(01 / 14384-$ 8) and CVPq (Grant nos. 302393/2003-0 and 302761/20098). The authors gratefully acknowledge the DENTSPLY De Trey GmbH Company, for donating the Xeno III adhesive and the phosphoric acid gel used in this study.

\section{References}

[1] Y. Leung and M. D. Morris, "Characterization of the chemical interactions between 4-META and enamel by Raman spectroscopy," Dental Materials, vol. 11, pp. 191-195, 1995. 
[2] M. Miyazaki, H. Onose, and B. K. Moore, "Analysis of the dentin-resin interface by use of laser Raman spectroscopy," Dental Materials, vol. 18, no. 8, pp. 576-580, 2002.

[3] M. B. Lopes, M. A. Sinhoreti, L. Correr Sobrinho, and S. Consani, "Comparative study of the dental substrate used in shear bond strength tests," Brazilian Oral Research, vol. 17, no. 2, pp. 171-175, 2003.

[4] M. Sato and M. Miyazaki, "Comparison of depth of dentin etching and resin infiltration with single-step adhesive systems," Journal of Dentistry, vol. 33, no. 6, pp. 475-484, 2005.

[5] I. Nakamichi, M. Iwaku, and T. Fusayama, "Bovine teeth as possible substitutes in the adhesion test," Journal of Dental Research, vol. 62, no. 10, pp. 1076-1081, 1983.

[6] M. S. Cenci, E. Piva, F. Potrich, E. Formolo, F. F. Demarco, and J. M. Powers, "Microleakage in bonded amalgam restorations using different adhesive materials," Brazilian Dental Journal, vol. 15, no. 1, pp. 13-18, 2004.

[7] R. B. Fonseca, F. Haiter-Neto, A. J. Fernandes-Neto, G. A. S. Barbosa, and C. J. Soares, "Radiodensity of enamel and dentin of human, bovine and swine teeth," Archives of Oral Biology, vol. 49, no. 11, pp. 919-922, 2004.

[8] S. Sauro, D. H. Pashley, F. Mannocci et al., "Micropermeability of current self-etching and etch-and-rinse adhesives bonded to deep dentine: a comparison study using a doublestaining/confocal microscopy technique," European Journal of Oral Sciences, vol. 116, pp. 184-193, 2008.

[9] F. Ozer, N. Unlu, and A. Sengun, "Influence of dentinal regions on bond strengths of different adhesive systems," Journal of Oral Rehabilitation, vol. 30, pp. 659-663, 2003.

[10] A. I. Abdalla, "Microtensile and tensile bond strength of single-bottle adhesives: a new test method," Journal of Oral Rehabilitation, vol. 31, no. 4, pp. 379-384, 2004.

[11] J. Xu, I. Stangel, I. S. Butler, and D. F. R. Gilson, "An FT-Raman spectroscopic investigation of dentin and collagen surfaces modified by 2-hydroxyethylmethacrylate," Journal of Dental Research, vol. 76, no. 1, pp. 596-601, 1997.

[12] Y. Wang and P. Spencer, "Analysis of acid-treated dentin smear debris and smear layers using confocal Raman microspectroscopy," Journal of Biomedical Materials Research, vol. 60, pp. 300-308, 2002.

[13] G. Penel, G. Leroy, C. Rey, and E. Bres, "MicroRaman spectral study of the $\mathrm{PO}_{4}$ and $\mathrm{CO}_{3}$ vibrational modes in synthetic and biological apatites," Calcified Tissue International, vol. 63, no. 6, pp. 475-481, 1998.

[14] Y. Wang and P. Spencer, "Physicochemical interactions at the interfaces between self-etch adhesive systems and dentin," Journal of Dentistry, vol. 32, pp. 567-579, 2004.

[15] Y. Wang and P. Spencer, "Hybridization efficiency of the adhesive/dentin interface with wet bonding," Journal of Dental Research, vol. 82, pp. 141-145, 2003.

[16] Y. Wang and P. Spencer, "Continuing etching of an all-in-one adhesive in wet dentin tubules," Journal of Dental Research, vol. 84, pp. 350-354, 2005.

[17] R. Schilke, J. A. Lisson, O. Bauss, and W. Geurtsen, "Comparison of the number and diameter of dentinal tubules in human and bovine dentine by scanning electron microscopic investigation," Archives of Oral Biology, vol. 45, pp. 355-361, 2000.

[18] L. E. Soares, A. M. do Espírito Santo, A. B. Junior et al., "Effects of Er:YAG laser irradiation and manipulation treatments on dentin components-part 1: Fourier transform-Raman study,"
Journal of Biomedical Optics, vol. 14, no. 2, Article ID 024001, 2009.

[19] A. C. T. Ko, L. P. Choo-Smith, M. Hewko et al., "Ex vivo detection and characterization of early dental caries by optical coherence tomography and Raman spectroscopy," Journal of Biomedical Optics, vol. 10, no. 3, pp. 1-16, 2005.

[20] M. B. Lopes, M. A. C. Sinhoreti, L. C. Sobrinho, and S. Consani, "Comparative study of the dental substrate used in shear bond strength tests," Pesqui. Odontol. Bras, vol. 17, pp. 171-175, 2003.

[21] S. Habelitz, M. Balooch, S. J. Marshall, G. Balooch, and G. W. Marshall Jr., "In situ atomic force microscopy of partially demineralized human dentin collagen fibrils," Journal of Structural Biology, vol. 138, no. 3, pp. 227-236, 2002.

[22] J. L. O. Tanaka, E. Medici Filho, J. A. P. Salgado et al., "Comparative analysis of human and bovine teeth: radiographic density," Brazilian Oral Research, vol. 22, no. 4, pp. 346-351, 2008.

[23] D. H. Pashley, H. Sano, B. Ciucchi, M. Yoshiyama, and R. M. Carvalho, "Adhesion testing of dentin bonding agents: a review," Dental Materials, vol. 11, no. 2, pp. 117-125, 1995.

[24] F. Wegehaupt, D. Gries, A. Wiegand, and T. Attin, "Is bovine dentine an appropriate substitute for human dentine in erosion/abrasion tests?" Journal of Oral Rehabilitation, vol. 35, no. 5, pp. 390-394, 2008.

[25] S. Bouillaguet, P. Gysi, J. C. Wataha et al., "Bond strength of composite to dentin using conventional, one-step, and selfetching adhesive systems," Journal of Dentistry, vol. 29, no. 1, pp. 55-61, 2001.

[26] A. A. Al-Ehaideb and H. Mohammed, "Shear bond strength of "one bottle" dentin adhesives," Journal of Prosthetic Dentistry, vol. 84, no. 4, pp. 408-412, 2000. 

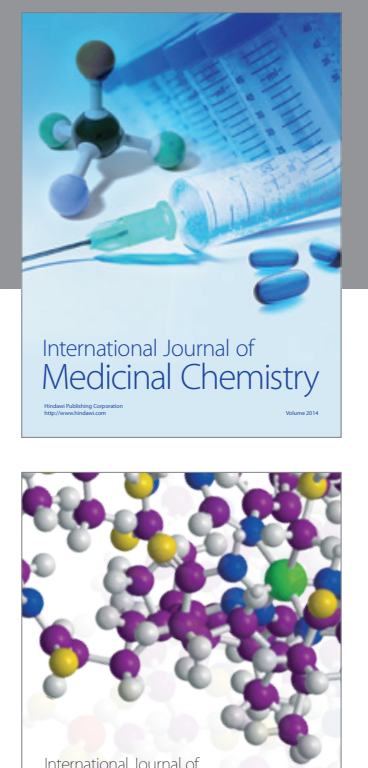

\section{Carbohydrate} Chemistry

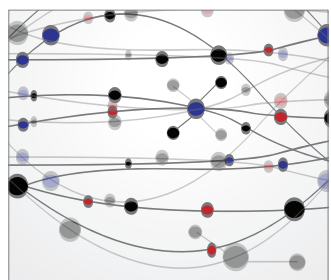

The Scientific World Journal
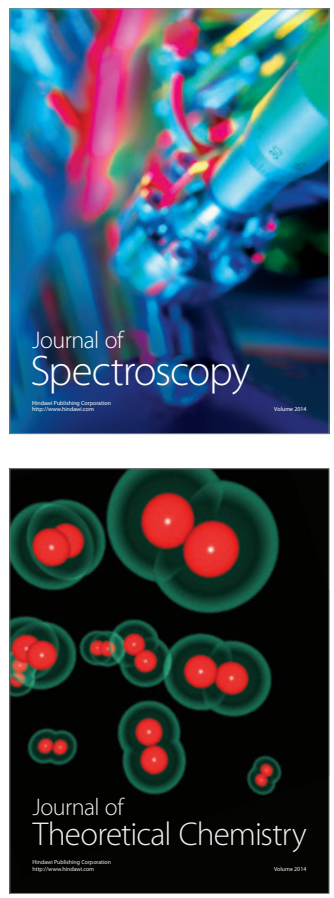
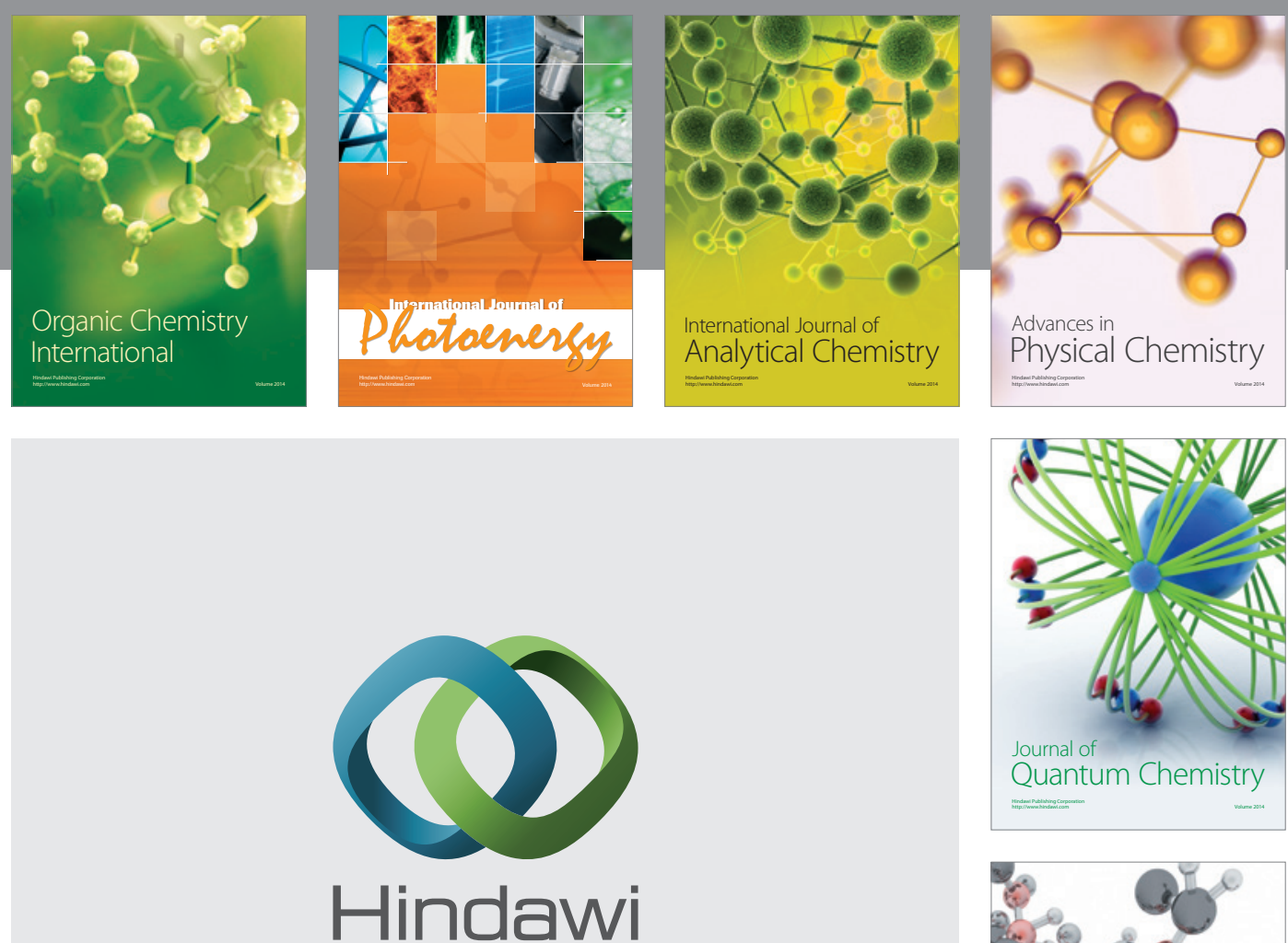

Submit your manuscripts at

http://www.hindawi.com

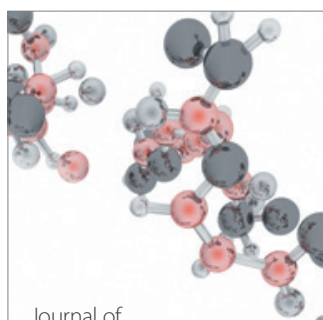

Analytical Methods

in Chemistry

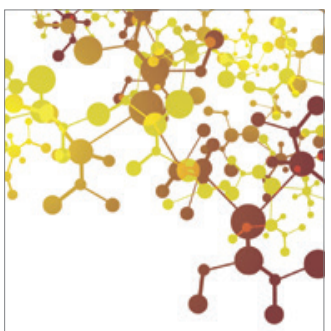

Journal of

Applied Chemistry

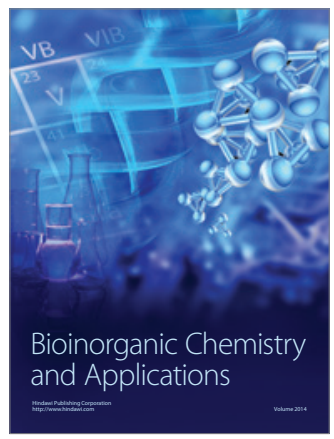

Inorganic Chemistry
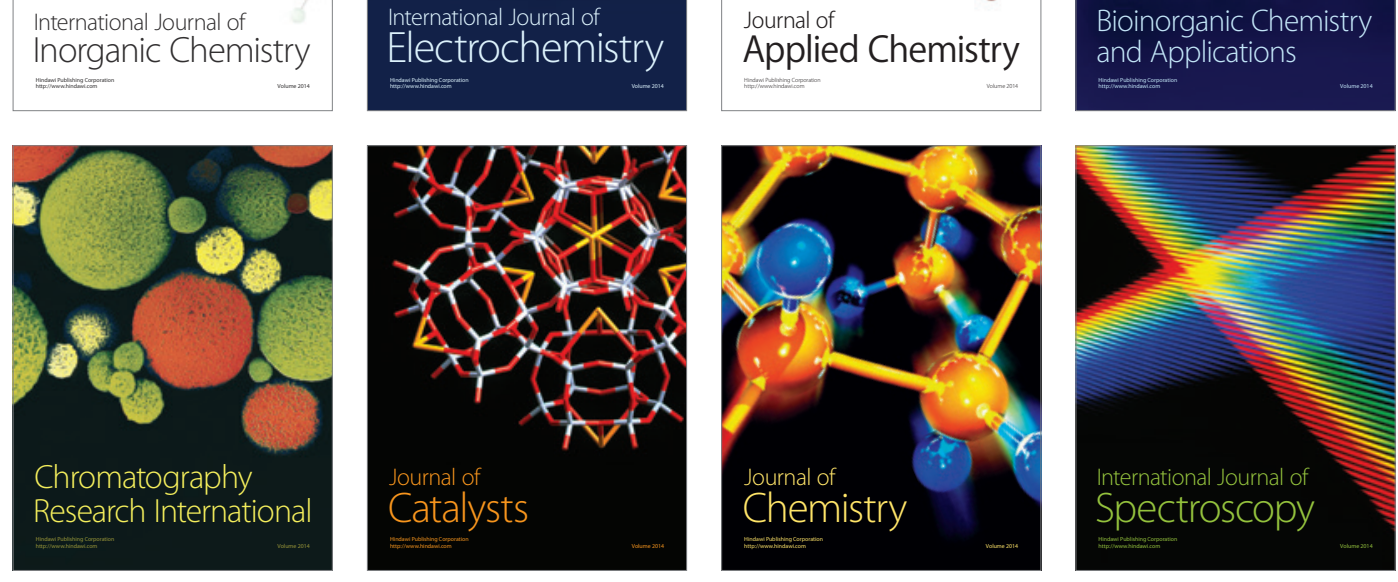